\title{
Cumhuriyetin 100. Yllında (2023) Türkiye ve Türk Üniversiteleri, Gerçekler-Çözümler
}

\section{Alexei BERECHELEA*}

Zaman geçtikçe her şey belli oluyor. Küreselleşme sürecinin içindeyken beş saniye sonra olabileceklerini tahmin edemeyiz bile. Fakat tarihin gelişmesine bakarak ve tarihi yorumlayıp on yedi sene sonra olabileceklerden haber vermeye çalışacağım. Tabi ki yazdıklarımın yüzde yüz gerçekleşebileceğini pek sanmıyorum; ama aynı anda tarihe dayanarak gerçeklere yaklaşmış ve öngörmüş olabilirim.

Türkiye iki bin yirmi üç yılında Avrupa Birliğine girmiş olacak. Bundan kaynaklanan bir çok değişikler olacak. Bir kere, ticaret alanları büyüyecek. Tabii ki ekonomi düzeyi artacak. Yoksulların, maaşın artmasıyla sayısı düşecek. İkincisi, kültür ve eğitim alanlarında düşünemeyeceğimiz kadar değişiklik yapılacak. Türkiye'nin nüfusu büyüyecek ve batılılaşacak. Çünkü Avrupa'nın kültürünü, eğitim düzeyini kabullenecek. Her insan eksiklerini giderecek. Başka kültürden en iyisini alarak kendi kültürünü de ekleyip hem toplumsal hem ruhsal düzeyi değișecek. Türkler yabancılara o kadar alışacaklar ki onların kültürlerini kendi kültürüyle ayrım yapamayacak düzeye gelecekler. Kendi kültürüne sahip olunca yabancı kültürlerin eksiklerini gidermek amacıyla en iyi ilkeleri benimseyecekler. Çünkü yalnız böyle yaparak gelişme sağlarlar.

Dünya tarihine bakarsak hep böyle olmuştur. Belirli bir kültüre dair olanlar başka milletlerin kültürlerinden etkilenerek gelişiyorlardı. $\mathrm{Bu}$ cümle ile Müslümanlığın terk edilmesi gerektiğini hiç kastetmiyorum. Tam tersine. Dinin sağlamlığını koruyarak kültürün gelişmesinin gerektiğini ifade etmeye çalışıyorum. Tabii belki din kültürün en temel unsurlarından birisidir; ama ben din ve kültür arasında ayrım yaparak nedenlerini de açıklayayım. Türk tarihine bakarsak eski Türklerin kimi Şamanlığa kimi Hıristiyanlığa dairdir. Fakat bana göre buna rağmen o zamanda Türk kültürünün ortaya çıkışı oldu. Yani Müslümanlığa geçmeden önce Türk kültürü oluşmuş ve

• Ankara Üniversitesi, İletişim Fakültesi, Gazetecilik Bölümü, 2. Sınıf Öğrencisi 
gelişmeye başlamıştı. Demek ki kültürün dinle bir ilişkisi yoktu. Demek ki yalnız dinden değil, hem hayat tarzından hem de siyasal düzenden, iletişimden ve başka unsurlarından etkilenerek Türk kültürünü yaşamaya başladı. Eminim ki o zamanlarda Türkler başka milletlerin kültüründen birkaç temel unsurları benimseyip etkilenmişlerdi. Bu süreç her zaman var olandır.

On yedi yıl sonra Türkiye dünyanın en eğitimli ve en kültürlü ülkelerinden birisi olacak. Çünkü Avrupa Birliğine girmesiyle birlikte yaşam tarzı inanamayacağımız kadar değişecek. Başka ülkelerdeki insanlarla iletişim kurmak adına Türkler yabancı dillerini hevesli bir şekilde öğrenmeye başlayacaklar. Böylece Türkiye ve yabancı devletler arasındaki kopulmaz bağı oluşturacaklar. Toplumsal, siyasal değişim inanılmaz hızlı bir biçimde gerçekleşiyor olacak. Türkiye bundan pek fayda sağlayacak. Türkiye nüfusu sağlıklı bir şekilde de artacak. "Nasıl?" diye sorabilirsiniz. "Bir dil bir insan, iki dil iki insan." Türkiye günlük hayatta küçük; ama sık sık olan sorunları giderecek. Türkiye'deki insanlar yabancı dilleri bilerek yurt dışından gelen tercümanlara ihtiyaç duymayacak. Çünkü Türkler yabancılarla ilgili en zor problemleri çözebilecekler. Devletin bir tek resmi dili olmasına rağmen buraya yurtdışından gelen göçmenler hiçbir zorluk çekmeden hayatlarını sürdürecekler. Çünkü bu zamanda Türkiye dünyanın ortak dillerini konuşabilen bir ülke durumuna gelecek. Örnek olarak Almanya'yı alalım. Almanya'da birkaç milyon Türk yaşıyor. Türkiye'den oraya gidenler hiç zorlamadan hayat kurabilirler. Bunun yanı sıra Almanca'yı ya da İngilizce'yi bilerek Türkçe'yi anlayabilmeleri ilk çıkan sorunlar üzerinde etkili olacak. Aynı süreç Türkiye'de de olacak. Yabancılar Türkiye'ye gelip sanki kendi ülkelerinde yaşıyormuşçasına rahat edecekler. Çünkü sokaktaki insanlar onları anlayabiliyor olacaklar. Üstelik öyle bir durum olunca yurt dışındaki uzmanlar da buraya çalışmaya gelecekler. Bununla birlikte Türkiye bütün alanlarda hem gelişmiş hem de iyi olan ülkelerinden birisi olacak.

Benim Türkiye hakkındaki düşüncem, iki bin yirmi üç yılında Türkiye'nin siyasal dizgesi, yaşam muhafazakarlı̆̆ında, toplumun bakış açısında büyük bir reformcu değişiklik olacak. Çünkü gelecek on yedi sene içerisinde iktidara tanzimatçı bir insan gelecek. Halk bu insana resmi olmayan lakap verecek. Ona "ikinci Atatürk " denilecek. Bu adam Türkiye'nin günlük sorunlarını, halkın zorluklarını çözecek . "Nasıl?" diye sorabilirsiniz. Kemal Atatürk gibi bugünkü yaşam tarzına dayanarak, toplumsal düşünceleri temel olarak alıp Türkiye'de "Yeni Tanzimat Dönemini” başlatacak. Müslüman, Budist, Hıristiyan dinleri bir tarafta bırakıp dünyanın bütün ülkeleriyle iyi dostça ilişkiler kurulacak. Dünyamıza barış getirecek Türkiye en büyük ülkelerinden biri olacak. Birinci bile olabilecek. "Yeni Tanzimat Döneminin en önemli ve güçlü sloganlardan biri şu olacak: "Yeni Türkiye yeni 
Türkler için." Fakat "Türkler" kavramıyla birlikte "Yeni Cumhuriyetin" bütün vatandaşları kastedecek. Türkiye'nin yeni toplumu bütün Dünya ülkelerinin en iyi ilkelerini benimseyecek. Böylece kendilerini daha üst düzeye çıkartacaklar. Üstelik "yabanc1" devletlerin en iyi taraflarını benimseyecekler. Bununla birlikte yoksulluk ve işsizlik oranı azalacak değil, tamamen giderilecek. "Yabancı" kavramı tırnaklara alarak da "Yeni Türkiye'de" yabancı kavramının manası tamamen ortadan kaldırılacağını ifade etmeye çalışıyorum. Çünkü; on yedi sene sonra dünyanın bütün insanları arasında hiçbir fark olmadığını anlayacaklar. Ne deri rengine, ne dinine, ne kültürüne bakılacak. İnsanlar "kardeşlik" kavramını taban alıp yaşam sürdürecekler. "Hepimiz kardeşiz, hepimiz insanız. Hepimiz birbirlerimizin akrabasıyız", diye düşünülecek. Böyle olacağına eminim. Çünkü zaman geçtikçe dünyayı bütün türlü kötülükten korumak amacıyla insanlar yazdığım gibi davranmaya başlayacaklar. Başka çare yok zaten. Başka bir şekilde de olmaz. Tam tersi davranış bizi bir uçuruma götürür. Üçüncü Dünya Savaşı başlarsa kıyamet günü bir hafta içerisinde gerçekleşmiş olacak. Fakat öyle bir sürecin gerçekleşmesine izin veremeyiz. Bu açıdan Türkiye çok etkili olacak ve yeryüzünde denge sağlayacak.

Fransız krallardan birisi şunu der: "Barışı sağlamak istiyorsanız savaşa hazır olun". Bence çok haklı bir söz. Çünkü; dünya tarihine bakarsak çoğu savaş barışı sağlamak amacıyla gerçekleştirilmiştir. Fakat bana göre yakın gelecekte savaş kavramı dilimizden gidecek. Daha önce de yazıldığı gibi Türkiye savunma açısından çok güçlü bir ülke olacak. Böyle bir duruma on yedi yıl içerisinde nasıl geleceğini anlatmam gerekiyor. "Yeni Türkiye'nin" Mehmetçik düzeninde pek fazla değişiklikler yapılmayacak; ama değişecek olanlara bir göz atmalıyı. İlk önce askerlerin yaşam şartları değişecek. İkincisi, askerlik yapma süreci bir seneden daha fazla olmayacak. Askerliği bitirince insanları hiçbir sınava girmeden direkt üniversiteye gitme imtiyazına sahip olacaklar. Kendi isteğiyle bir yıldan daha fazla askerlik yapmak isteyenler toplumsal imtiyazları kullanma imkanına sahip olacaklar. Böylece "Yeni Türkiye'nin" ordusu hem sayıda, hem eğitimli, hem de çok güçlü olacak. Dolayısıyla dünyamızın kaderini belirleyen devletler artık Türkiye'yi de ciddiye alması gerekecek.

$\mathrm{Ne}$ yazık ki kimi ülkelerde çok, kimi ülkelerde az yoksul vardır. Tabi ki bu sorun bir bireysellik bir dert değildir. O bir toplumsal problemdir. Bana göre bu sorunun temeli eğitimsizlik ve işsizliktir. Eğitim görme hakkına sahip olanlar maddi değerlere sahip olmayınca ilkokula bile gidemez hale geliyorlar. Demek ki herkes belirli bir işe sahip olunca çocuklarını okula gönderebilir hale gelecek. "Yeni Türkiye'de" bu sorun yazdığım gibi değişecek. Ayrıntılarına girersek ortaya önemli bir sonuç çıkıyor. Ülkemizde on yedi yıl geçemeyecek bile işsizlik oranı yüzde sıfır olacak. Bu kadar büyük bir ülkede 
herkes için bir işin var olduğuna inanıyorum. Böylece daha önce eğitim görmeyenler köylü insanlar üniversiteyi, yüksek lisansı bitirme hakkı tanınacak. Eminim küçük kasabalarda ve köylerde yaşayanlar arasındaki dehalar vardır. Yalnız eğitim görmediğinden istidatları gömüyorlar. "Yeni Türkiye'de" eğitim herkes için olunca bu dehalar yeni keşif yapıp ülkemizin imajını arttıracaklar, ülkemizi bir düzeye eriștirecekler. Bununla birlikte Türkiye'ye rakip olabilecek bir ülke olmayacak. Neden böyle düșündüğümü de açıklayayım. Devletimizin nüfusu çok büyük. Demek ki çok akıllı devrimci insanlar vardır. Onlar Türkiye'nin geleceği sağlayacaklar. Onlara bir firsat verilirse bu firsatı asla kaçırmayacaklar. Hem de eğitimli toplumda bütün sorunlar barış yoluyla çözülüyor olacak. "Yeni Türkler" daha önce düşünülmemiş teknolojilere sahip olacaklar. Yeni fabrikalar açılacak. Elbette ki uzmanlara ihtiyaç duyulacak. Böylece yurt dıșından uzmanları getirilmeyecek yerine Türk vatandaşları çalıştırılacak. Engelliler eğitimi tamamen ücretsiz görecekler. Çünkü; onların da Türkiye'ye bir faydası olacak. Her eğitimli vatandaş bir buluntudur. Her eğitimsiz olan bir kayıptır. Eğitime çok fazla önem vermemiz gerekiyor. Çünkü anladığımız gibi bütün sorunlar ondan kaynaklanıyor. "Yeni Tanzimat Döneminde" rüşvet ve benzeri olaylar ortadan kaldırılacak. Çünkü; eğitimli kendine saygı duyan insan vicdanına karşı çıkmak istemeyecektir. Üstelik vatandaşların maddi durumu iyi olacağ kaynakları bulmaya çalışmaktan vazgeçecekler.

"Yeni Türkiye'de" hükümetin kontrol altında gelişme sürecinin en temel unsurlarından biri bulunuyor olacak. Devlet topluma kitap okumayı sevdirecek. İlkokuldan itibaren en çok okuyanlar ve en çok bilenler ödüllendirilecekler. Böylece okuma hevesi sağlanacak. Yeni kuşaklar kitap okurken uygarlığımızın zarar verici uğraşlardan farkında olmadan uzak tutulacaklar. Anne babalar daha mutlu dönem geçeceğinden insanlar ikinci çocuğa da sahip olmak isteyecekler. Aileler, vatana millete yararlı çocuklar yetiştirecekler. Artık hiç sakat insanlar doğmayacak. Çünkü; herkes üremeyle ilgili yeterli bilgilere sahip olacak. Bununla birlikte eski hastalıkların ilacı bulunup yeni hastalıkların ortaya çıkmasına ve salgın gibi büyük sağlık sorunlarının ortaya çıkmasına izin verilmeyecek. Çünkü; her insan sağlığına daha fazla önem verip yanındaki yaşayanlara saygı duyacak. Sağlıklı toplum, sağlıklı devlet demektir. Sağlıklı devlet ise hızlı gelişme demektir.

Eğitim, toplumları ve dünyamızı inkişaf ettirilen ve geliştiren en temel öğelerinden birisidir. Ona önem vererek imkansızlığını gerçekleştirebilir hale geliyoruz. Çünkü; o hem "barış" hem "savaş" aygitıdır.

Eğitim gelişmesi gösteren temel unsur dershanelerin kaldırılması olacak. Çünkü değişecek olan eğitim süreci öğrencilerin ilkokuldan liseye kadar yeterli bilgilere sahip olma imkanı sağlayıp dershanelere 
duyulan ihtiyaç ortadan kalkacak. Tabi ki şu anki Türkiye'de yazdıklarım biraz imkansızdır; ama zaman geçtikçe değişmez olan kalamayacak. Çünkü; "Yeni Dönemde" hükümet eğitimsizlik ve kültürsüzlükle savaşmak için daha fazla çaba gösterecek. Eğer yazdığım gibi olursa her öğrenci liseyi bitirdikten sonra hemen üniversiteye gitme olanağ1 kazanacak olur. Hem de eskisi gibi olmayacak. Yani üniversiteye gitmek için ÖSS'ye girenlerden yüzde doksan beşi üniversitede okuma fırsatı elde edebilecek. Demek ki geri kalan öğrenciler ya ikinci defa sinava girecek ya da KPSS'ye girip devlet memuru olarak çalışacak. Böylece eğitim süreci herkes için olabilecek. Aynı anda kaldırılacak olan dershaneleri insanların büyük paralar harcamama fursat vermeyecek. Bu yüzden her ailede bu kadar fazla para olunca çocuklarını ya Türkiye'nin en iyi üniversitesinde okutma imkanı ya da yurt dışında eğitim görebilme şansı sağlayacak. Anladığımız gibi lise eksiklerini gidermek amaciyla kullanılan para (dershanelere gitme) artık öğrencilerin üniversitedeki maddi zorluklarını çözmeye yarayacak.

Bildiğimiz gibi eğitimin gelişme düzeyi ilkokuldan itibaren anlaşılmaya başlanıyor. Fakat; bu gerçeği yalnız üniversitelerin öğretim süresine bakarak anlayabiliriz. Bundan dolayı "Yeni Türkiye'nin" üniversitelerinin bulunduğu durumu anlatmak gerektiğine inanıyorum.

"Yeni Tanzimat Döneminde" Türkiye üniversiteleri dünyada ilk sıralarda olacak. Çünkü; yüksek düzeyli eğitim yeni devrimci öğretmenlerin olmasını sağlayacak. Eğitim sisteminde birkaç değişiklik yapılacak. İlk önce bütün sınavlar bilgisayar tarafından yapılacak ve kontrol edilecek. Ayrıca her öğrencinin kopya çekme olanağının önüne geçilecek. Üniversite imtihanına girmeden önce her hangi kağıt ya da elektronik aygıtına sahip olup olmadığını bilgisayar tarafından kontrol edilecek. Sınav boyunca öğrencilerle birlikte birkaç kamera ve bilgisayar dışında hiç kimse olmayacak. Her öğrenci sıra gelince bilgisayara yaklaşıp ve kendi kartı göstererek sınav kağıdını alacak. Kurallar çok sert olacak; ama bundan sonra yalnız okumaya ihtiyaç duyanlar ders görecek. Üniversiteyi bitirmek isteyenlerin sayısı artacak. Çünkü; daha önce yazdığım gibi herkes için bir iş olacak. Uzmanlaşma başlar başlamaz Türkiye'nin ilerlemesini durdurulamaz hale gelecek. Üniversiteyi bitirenler yüksek lisansı yapmak istediği sürece genel ve LES' ten daha adaletli sinav yapilacak. Yani siyasal kesitte okuyanlar için sınavda daha fazla fen bilimlere vurgulandırılacak, sosyal kesitte okuyanlar için ise daha fazla sosyal bilimlere vurgulandırılacak. Üstelik yurt dışında yüksek lisans ve staj yapmak isteyenler için çeşitli yarışmalar düzenlenecek. Türkiye'nin en iyisi ve en hak edilen öğrencileri vatanı temsil edecek. Bununla birlikte yurt dışında Türkiye ile ilgili imaj iyeleştirilecek.

Artık Türk üniversitelerinde eğitim birkaç dilde verilecek. Her öğrenci kendi isteğiyle Türkçe dışında bir dil seçecek. Seçilen dilde 
eğitim görüp aynı anda iki yabancı dil daha öğrenecek. Elbette ki bu çok fayda sağlayacak. Çünkü o andan itibaren Türkler kolaylıkla yabancı kültürü öğrenip, eleştirerek en iyi olanları kendi kültürüne ekleyecek. Türk üniversitelerinde çok başarılı olanlar için burs imkanı sağlanacak. Ayrıca her sınıfta ortalamaya göre ilk üç öğrencinin yüzde yetmiş beşi ücretsiz eğitim görecek. Ondan sonra ilk on en iyi öğrenciye yüzde elli indirim yapılacak. Böylece öğrencilerin arasında rekabet sağlamış olacak. Her sene Türk üniversitelerin her fakültesinde en iyi öğrenci seçilip ücretsiz olarak yurt dışına gönderilecek.

On yedi yıl sonra herkesin bir bilgisayara sahip olacağ1 için kitap satın alma ihtiyacı ortadan kalkacak. Çünkü; öğrenciler bütün ders kitaplarını artık internette bulabilir hale gelecek. Üniversitedeki kütüphaneler artık pek fazla kalabalık olmayacak. Öğrenci gerekli kitabı bulup onu evinde ya da parkta okuyabilecek. Bununla birlikte kitabın talebi düşünce ucuzlama süreci başlayacak. Artık kitabı almak isteyenler pek fazla para harcamayacak. Düşük gelire sahip olanlar da satın alabilecek.

Disiplin ile ilgili değişiklikler de yapılacak. İlk önce bütün Türk üniversiteleri öğrencilerinden gerektiği gibi davranılması istenecek. Bu kural uymayanlar kameralar tarafından belirlenecek. İkincisi, üniversitelerde kampusun içinde sigara ve içki içilmesi yasaklanacak. $\mathrm{Bu}$ kurala uymayanlara para cezası uygulanacak. Üçüncüsü ise, her Türk üniversiteleri öğrenciler hiç istisnasız öğretim süreci boyunca belirli giyimle okula gelecek. Kurala uymayanlar bir defa uyarılacak. İkinci kez üniversiteden atılacak. Dördüncüsü, bir dönem boyunca görülen derse üç defa gelmeyen öğrenci üniversiteden atılacak. Türk üniversitelerinde bütün dersler saat dokuz buçukta başlanacak ve en fazla akşam beşe kadar sürecek. Hafta sonu günlerinde ders ya da sınav yapılmayacak. Her hangi bir derse beş kez geç kalan öğrenciler bu derste otomatik olarak kalacak. Ders içerisinde kural dışı her hangi bir davranış yapanlar cezalandırılacak. Yazdığım gibi olunca Türk üniversiteleri etik bir kurum haline dönüşecek.

Bunun dışında belirli ortalamaya sahip olan öğrencilere ücretsiz servis avantajı sağlanacak.

Gördüğümüz gibi "Yeni Türkiye'nin" üniversite sistemi bütün alanda düzen, okuma rekabeti ve keşfetme yapanların ödüllendirilmesini sağlayacak. Aynı anda Türkiye'nin ilerlemesinde de önemli bir rol oynayacak.

Bana göre muhafazakarlığın hem olumlu hem de olumsuz yönleri vardır. Fakat; eminim ki muhafazakarlık uzun zaman içerisinde ilerlemiyorsa gerileme süreci başlıyor. Bu kadar büyük, zengin bir ülke neden geri kalmalı ki. Aksine, her yıl ilerleme süreci içinde bulunmalı. Türkiye'nin yavaş gelişmesi görünce aklıma ilk gelen fikir devrimdir. 
Fakat siyasi devrimi kastetmiyorum. Toplumsal, akılsal, ruhsal devrimden bahsediyorum. Tabi ki Türkiye'nin ilerlememesi ile ilgilenler var. Bu normal bir süreçtir. Muhalefet her zaman vardı. Muhalefet olunca demokrasi de var demektir. Fakat insanları böyle devam etmemesi gerektiğini anlaması gerekir. "Dur, bu kadar yeter", diye söyleyip kendi çabalarıyla yardımcı olmalı. Türkiye'nin kaderi hükümetin değil halkın ellerindedir. Herkes bir eylem yapsa bu iş başarılabilecektir. En azından her bireyin şunu düşünmesi gerekir: "Ben yapmazsam, kim yapar?" Bunu düşünenlerin sayısı ne kadar çok olursa Türkiye o kadar hızlı gelişir. Tarihi yapan insan değil, tarihi yapan halktır. Bu yüzden Türkiye'nin parlak geleceğine inaniyorum. Akıllı olanlar çok demek ki gelişme sürecinin yıldan yıla artacak. Türkiye en yüksek refah seviyesine ulaşacak. 